\title{
Comprehensive AIDS prevention programs in prisons: A review study
}

\author{
Somayeh Zare ${ }^{1}$, Mehdi Kargar ${ }^{1}$, Jeyran Ostovarfar ${ }^{1}$, Mohammad Hossein Kaveh ${ }^{1}$
}

\section{Abstract}

Objective: Since prisoners may acquire AIDS and transmit HIV because of highly risky behaviors, implementation of educational and therapeutic programs is important in decreasing the prevalence of AIDS and transmission of HIV. This study was conducted to recognize different types of interventions and compare their effectiveness regarding prevention of AIDS and its control in prisons.

Methods: The ISI, PubMed, Google Scholar, databases were searched with use of "AIDS," "prison," "HIV," and "incarceration" as keywords from January 2000 to March 2017, with access to free full text and English language as limitations. Related articles, including observational, epidemiological, case, and interventional studies, were extracted and those inconsistent with the study's goals were excluded.

Results: Forty-three studies were finally selected. The effectiveness of interventions related to AIDS prevention and control in prisons was studied.

Conclusion: It seems that theory-based studies conducted with stakeholders participation and evaluated summatively are more successful, because they give a sense of ownership. In addition, considering prison as a setting can lead to more success of these programs.

Keywords: AIDS; prison; intervention; prevention
1. Health Education and Health Promotion Department, Health School, Razi Street, Shiraz, Iran

CORRESPONDING AUTHOR: Mohammad Hossein Kaveh

Health Education and Health Promotion Department, Health School, Razi Street, Shiraz 71536-75541, Iran

E-mail: Kaveh@sums.ac.ir

Received 14 February 2018; Accepted 11 July 2018

\section{Introduction}

Prison is a highly populated place in which the prevalence of many diseases is attributed to low level of knowledge and prisoners' cultural poverty and disregard of ritual and social principles [1]. Studies show that highly risky behaviors in prisons such as drug injection make prisoners prone to viral infections, including hepatitis C, hepatitis B, and HIV infection. Their prevalence among incarcerated adolescents and young adults is sometimes more among the ordinary population in every society. A number of them are incarcerated for short periods, and some of them are freed temporarily, and so they maintain contact with society. Those with drug addiction are not only exposed to dangerous diseases themselves but also they can also play the role of a carrier to transmit diseases to other people [2, 3]. The first case of AIDS in prisons was reported in 1982 [4]. A study in 2002 in Canada showed that the prevalence of AIDS was 3.71\% among female prisoners and $1.96 \%$ among male prisoners [5]. The prevalence of HIV positive was 1.6 and 1.9 percent respectively for male and female inmates [6]. According to a World Health Organization (WHO) report from 2017 [7], the prevalence of AIDS in 
prisoners is about $3.0 \%$, which is 15 times more than the prevalence in the normal population. It also reported that $5.0 \%-$ $10.0 \%$ of prisoners are women, and the prevalence is higher among them in comparison with male prisoners. The findings indicated that the number of female prisoners increased by $16.0 \%$ in the previous 6 years [7]. Comprehensive prevention programs related to AIDS in prisons suggested by WHO include educational programs connected to AIDS, needle syringe programs (NSPs), condom distribution programs, and medical therapy programs [8]. However, no comprehensive and integrated programs have been suggested by WHO for prevention of HIV infection among prisoners. Meanwhile, it is necessary to review the current programs and also their effectiveness so as to plan, develop, and implement the interventions. This study was done to investigate comprehensive interventions and their effectiveness for prevention of AIDS and its control in prisons.

\section{Methods}

The PubMed, Google Scholar, and ISI databases were searched with use of the keywords "prison," "HIV," "AIDS," and "incarceration" from January 2000 to March 2017. Articles written in English and available as free full text were selected for review. Related articles (including cohort, descriptive, interventional, and qualitative studies) were extracted. Also, credible reports and statistical figures from WHO were investigated.

First, the title of every article was assessed by two different researchers individually. Then, articles not meeting the inclusion criteria were excluded. The left articles were studied with emphasis on AIDS preventive programs and interventions related to them.

\section{Results}

Forty-three original studies, including nine systematic analyses and meta-analyses, 14 randomized controlled trials, two cohort studies, six case studies, seven cross-sectional studies, four qualitative studies, and one mixed investigation, two books, two articles from WHO website, and one article from the Canadian HIV/AIDS Legal Network were studied. In all mentioned studies, the effectiveness of educational and therapeutic interventions provided for prisoners for AIDS prevention and control were investigated.
The studies and interventions presented in this investigation are as follows: educational programs related to AIDS, HIV counseling and testing programs, provision of condoms, other measures to decrease sexual transmission, NSPs, bleach and decontamination strategies, safe tattooing programs, opioid substitution therapy, and other drug dependence treatment.

\section{Educational programs related to AIDS}

The studies show that the effectiveness of these programs should be investigated more. They can be effective when they are implemented extensively. The studies suggested some ways to make these programs more effective. The suggestions consisted of providing educational programs on AIDS and other infectious diseases for prisoners and prison staffs, providing individual educational programs for them, and access to condoms and syringes [9]. Dolan et al. [10] implemented an educational programs related to HIV in Siberia. They presented the importance of disease and its transmission routes, risk factors, signs, and possible treatments in educational sessions by means of brochures and films. They found that knowledge of disease and transmission routes increased significantly among drug-dependent male prisoners after intervention rather than before intervention.

A study conducted in Nigeria among prisoners in Lagos illustrated that few of them knew about AIDS and that most of the prisoners were prone to acquire this disease because of lack of knowledge. It was suggested that a comprehensive educational program should be provided for them [11].

In Brazil, Alves Peres et al. [12] studied the knowledge, attitude, and practices of male prisoners and the effectiveness of an educational program. They concluded that the best improvement would not be achieved unless educational programs would have been provided based on the prisoners' needs. They also found that use of graphic and visual materials such as music, educational pamphlets, and educational films could increase prisoners' participation and their knowledge and improve their attitude and practices.

Moreover, Petrova and Garcia-Retamero [13] studied the effectiveness of educational programs for infectious diseases transmitted through sexual intercourse. They found that such programs could decrease the risk of disease transmission by $4.0 \%$. Fogel et al. [14] conducted a randomized controlled 
trial among American female prisoners to find the effectiveness of a behavioral intervention (Providing Opportunities For Women's Empowerment, Risk-Reduction, and Relationships, or POWER) in decreasing the HIV-sexually transmitted infection (STI). The results indicated that the prisoners in the intervention group had a higher level of knowledge than the prisoners in the control group. The number of risky behaviors was lessened significantly among the prisoners in the intervention group. These programs could diminish the prevalence of contagious diseases such as AIDS among prisoners. However, this reduction was not significant. Fasula et al. [15] and Fogel et al. [16] showed that knowledge development should not be the only field of concern, and that cooperation of different sectors, including prison officials, researchers, and healthcare personnel, must be considered to decrease the present problems and develop effective educational programs.

\section{HIV counseling and testing programs}

These programs are conducted at the beginning of incarceration and during incarceration. Although they are not the main part of the comprehensive programs in prisons, they provide a chance for prisoners with a diagnosis of HIV infection to have easy access to preventive devices and to control highly risky behaviors. Some studies have demonstrated the effectiveness of these programs, such as easy access to counseling and diagnostic tests for all prisoners, and also access to therapeutic methods for HIV-positive prisoners [17, 18]. A study indicated that the rate of requests for these tests ranged from $39.0 \%$ to $83.0 \%$ among prisoners [8]. Some investigations have presented important influencing determinants related to doing these tests. They included doing the test in front of other people, unsuitable counseling services, and lack of continuous follow-ups [19-21].

An investigation was conducted to change the attitude of incarcerated adolescents and also improve their knowledge, self-efficacy and behavioral intention about using condom. The most significant change was seen in the knowledge of using condoms. It was shown that HIV preventive interventions succeed when they are precisely based on theories and evaluation [20]. Another study was conducted in Taiwan among substance-dependent prisoners according to the transtheoretical model [19]. It was effective in changing positively their knowledge of AIDS, self-efficacy related to highly risky behaviors associated with this disease, and also their readiness to change. 22.1 percent of the participants took the advantage of an educational program by stepping toward the next stages of change. This research revealed the considerable role of the transtheoretical model in prisoners by providing positive chances to change. This will happen if personal motivation and motivation-related needs are considered in the earlier stages of change.

Maryland's prevention case management program was applied in an investigation among female prisoners. It showed positive changes in behavior intention and attitude toward condoms, self-efficacy for condom use, and decease in injectedsubstance abuse [17].

Motshabi et al. [22] studied a counseling program for diagnostic testing in one of South Africa's prisons. They found a converse correlation between health condition and agreement to undergo diagnostic testing. However, there was no correlation between demographic characteristics and willingness to undergo diagnostic testing.

Roshanfekr et al. [23] investigated the effectiveness of harm reduction programs among addicted prisoners in seven Iranian prisons. Diagnostic tests performed at the beginning of incarceration revealed that $57.0 \%$ of prisoners used substances such as amphetamines, cannabis, and morphine. Two months later, the tests were repeated for those prisoners, and it was shown that $10.0 \%$ of them still abused drugs. This research proved that diagnostic test programs and counseling result in simultaneous decreases in substance abuse and highly risky behaviors among prisoners.

\section{Provision of condoms}

A number of studies have reported provision of condoms in prisons free of charge based on WHO's comprehensive program. Most of them have proven the effectiveness in preventing the transmission of HIV by sexual contacts. However, some of them mentioned the shortage of this provision among prisoners [24]. Yap et al. [25] indicated that free access to condoms in prisons in New South Wales led to increase their use during 5 year-study period. In addition, WHO suggested the following measures making the program more effective: free-of-charge provision of condoms, easy access to condoms, presentation of 
the program to prisoners and prison officials, and easy access to condom provision programs in prisons [26]. Dolan et al. also found that 52 and 25 percent of the prisoners used condom in, respectively, their anal and oral sex behaviors [27]. May and Williams [28] showed that condom provision can decrease the transmission of sexually related infections significantly. Leibowitz et al. [29] achieved the same results. Moreover, they concluded that the expenses related to AIDS treatment were also diminished. Harawa et al. [30] studied the sexual behaviors of prisoners and the rate of condom use among prisoners in the United States. They indicated that condom provision can lessen the transmission of HIV drastically in spite of the high level of risky sexual behaviors among the prisoners studied. Fundamentally, condom provision is one of the main parts of AIDS prevention, and the conducted studies have shown its success. Also, they concluded that prison officials supported the condom provision program more than before. In other words, prisoners use condoms as long as they have access to them [29, 31].

\section{Other measures to decrease sexual transmission}

The reports from different countries indicate sexual harassment and other forms of sexual aggression as one of the problems in prisons. They lead to health problems such as AIDS and other sexual diseases. There are some ways to solve this problem through determining strategies to diagnose, prevent, and decease all forms of sexual aggression in prisons, establishment of therapeutic methods for victims (postexposure prophylaxis), and also peer education [32, 33]. A study conducted in Lebanon investigate the conditions in prisons [33]. It revealed that prisons should be considered as a community and their members should be take into account more. Although these strategies have some shortcomings, they lead to improved life quality of prisoners.

\section{Needle and syringe programs}

Since substance injection is so widespread in prisons around the world and leads to increased risk of infectious diseases, needle and syringe provision among prisoners is recommended. Several studies have reported use of such programs in most prisons in many countries. They indicate that such a program has been accepted by prisoners who inject drugs. This has resulted in reduction of common use among them and, consequently, diminished HIV infection incidence [34-36].

Mogg and Levy [37] indicated that the potential efficacy of programs to change attitude or the behaviors related to NSP in prisons has not been investigated. However, there are some theories for justifying this failure. Social marketing, cognitive behavioral psychology, social identity theory, and peace studies declaring peoples' viewpoints about NSP should be reevaluated if they are convinced to discuss an NSP or not. Also, the participation of all stakeholders, such as prison officials, can give a sense of ownership and assist in the success of the programs. Sawangjit et al. [38] found that inclusion of NSP in other therapeutic programs can increase their effectiveness rather than programs without an NSP. In comparison with the total life-time cost of 55640 dollars for treatment of an individual with HIV, it can be decreased from 0.8 to 2.1 percent by implementing NSPs.

Some studies indicated that NSP leads to a considerable decrease in common syringe use and the possibility of disease transmission among prisoners. Also, it can diminish the abuse dose and mortality associated with substance overdose $[34,39]$.

\section{Bleach and decontamination strategies}

One of the strategies for reduction of harm from HIV infection includes using decontaminating materials for sterilization of syringes/needles. Decontaminants have been distributed in many prisons in different countries, such as Canada, Iran, France, Indonesia, and Australia. The effectiveness of these materials in prisons is not known yet, but this program can be used as a supporter of NSP in prisons [8].

Jürgens et al. [36] studied Canadian prisons. They revealed that it cannot be stated that provision of decontaminants in prisons can necessarily decrease transmission of infections among prisoners.

\section{Safe tattooing program}

Some studies have reported suitable facilities and devices that makes tattooing safe. It can be suggested to prisons' officials performing themselves some affairs such as tattooing for prisoners in a safe way. 
Hellard et al. [40] studied tattooing in the prisons of Austria. They found that 27 percent of the cases had been tattooed by the shared use of syringe or needle. Prisoners who injected drugs were more likely to have acquired a tattoo in prison in comparison with other prisoners, and $41.0 \%$ of tattooed participants had been tattooed in prison.

A study conducted in Canada indicated that some measures, such as providing suitable places for doing tattooing safely and safe tattooing educational programs, lead to decrease disease transmission. The advantages of such programs include decreasing disease incidence and the risk of disease transmission, the protection of prisoners and prison officials against disease, and development of people's awareness of diseases transmitted through blood [41].

A study in Canadian prisons considered tattooing as a risk factor for hepatitis C virus infection and HIV infection [42]. Qualitative and quantitative data were obtained from five prisons in which tattooing was done and the history of injecting drugs existed. The study affirmed the necessity of tattooing safely with regard to sterilization for supporting health in prisons. The interviews showed multiple dangers existed in tattooing innately that should be modified by the implementation of safe tattooing programs [42].

\section{Opioid substitution therapy and other drug dependence treatment}

Methadone maintenance therapy (MMT) has been used in all prisons around the world. The studies indicated the effectiveness of MMT in minimizing the drug injection dose and decreasing common syringe use. The advantages of this method also include protecting prisoners' health and that of their counterparts. Other medical therapies have not been effective in preventing AIDS. However, few investigations have been conducted on the effectiveness of these methods [43-45].

Farnia et al. [46] showed the effectiveness of MMT in decreasing opioid abuse in prisons and transmission of diseases through blood among Iranian prisons. From 2000 to 2008, the number of prisoners who received MMT increased from 100 to 25,000. Torrens et al. [44] found in their study in Spain that MMT can lessen the risk of HIV transmission. Larney et al. [47] studied the impact of opioid therapy programs in diminishing substance abuse in prisoners after their release and return to prison in Australia. They revealed that these programs could decrease repetitive incarceration about $20.0 \%$ among such prisoners.

Some factors can increase the effectiveness of such programs. They include use of skillful and trained staffs, provision of special guidelines with definite goals and their effective performance, and encouragement of governmental and nongovernmental organizations to participate in these programs [48]. Qualified communication among clients and prison officials assure prisoners that they will not be sued to be prosecuted after release from prison during their treatment course, and improving follow-up systems are some suggestions to develop these programs [47].

\section{Conclusion}

The studies showed that suitable design of educational programs can affect prisoners' awareness of AIDS. However, it is not easy to study their effectiveness. So, we posed the question of whether these programs affect significantly the decrease of HIV transmission among prisoners.

Counseling and diagnostic testing are not considered as the final goals of these programs, but they help to diagnose and treat AIDS and also provide supportive programs for prisoners and decrease the risk of HIV transmission to them.

Condom provision programs have been used effectively in several countries. The studies indicate that these programs have been supported more than before by officials and prisoners. They also showed if prisoners have access to condoms, they use them in their sexual contacts.

The investigations illustrated the importance of NSPs whenever AIDS is prevalent. They lead to lessening of the risk of HIV transmission and also extra expenses for disease therapy.

The investigations showed the effectiveness of medical therapy programs related to AIDS. MMT, as one of the most preventive and AIDS control therapies, can be effective whenever it is given appropriately. MMT can diminish the frequency of medicine use and also use of a common syringe. Principally, effective and accessible therapies influence health and safety in prisons. However, few studies have been conducted to determine the impact of decontaminant provision 
and safe tattooing programs in prisons, so it is not easy to evaluate their effectiveness.

Theory-based interventions conducted with the participation of stakeholders and evaluated summatively seemed to be more successful. This was because of cooperation to perform them. On the other hand, prison should be viewed as a setting holistically and all its parts, including prisoners, prison staff, prison management, the prison environment, and the family members of the prisoners, must be taken into consideration.

Finally, it can be concluded that multidimensional interventions are more effective in diminishing the incidence and prevalence of AIDS in prisons rather than establishing every single intervention individually.

\section{Acknowledgments}

We thank colleagues and the anonymous referees for their valuable comments.

\section{Author contributions}

MHK contributed to the design of the study, performed the interviews, and interpreted the interviews. MHK and SZ analyzed the data, wrote the draft, and revised the content. MK \& JO contributed in searching the articles, analyzing the findings and providing the final manuscript. All authors approved the final article.

\section{Conflict of interest}

The authors declare that they have no competing interests.

\section{Funding}

No funding support from any sources.

\section{Ethical considerations}

Ethical matters (e.g. plagiarism, uninformed consent, misconduct, data fabrication and/or falsification, double publication and/or submission, and redundancy) have been totally observed by the authors.

\section{Significance statement}

Prison is a highly populated place in which the prisoners are considerably prone to HIV/AIDS. This is mainly due to the prevalence of risky behaviors among them. Moreover, this population deprive of the effective preventive cares in all preventive levels. However, different programs have been implemented to diagnose, prevent and treat HIV/AIDS in prisons in the last decades. Meanwhile, no single review article has been done up to the end of monitoring process of the studied articles in which these measures would have been illustrated based on comparing their effectiveness. The present study aimed to recognize the most important AIDS preventive programs conducted in prisons from 2000 to 2017 through a review article.

\section{References}

1. Shams AS, Nasiri KM, Sharifi I, Khajeh KAM, Pourlashkari M. Prevalence of infectious skin diseases in the central prison of Kerman. Iranian Journal of Dermatology 2000;4(13);19-25. Available from: http://iranjd.ir/abstract.asp?articleID=1084.

2. Butler T, Boonwaat L, Hailstone S, Falconer T, Lems P, Ginley T, et al. The 2004 Australian prison entrants' blood-borne virus and risk behaviour survey. Aust N Z J Public Health 2007;31(1):44-50

3. Sampson LA. Opportunities for addressing the STD epidemic through interventions targeted to North Carolina's incarcerated populations. N C Med J 2005;67(5):374-7.

4. Wormser GP, Krupp LB, Hanrahan JP, Gavis G, Spira TJ Cunningham-rundles S. Acquired immunodeficiency syndrome in male prisoners: new insights into an emerging syndrome. Ann Intern Med 1983;98(3):297-303.

5. Canadian HI, Network AL. HIV/AIDS in Prisons in Central and Eastern Europe and the former Soviet Union. Bleach and other disinfectants (Info sheet 5). Montreal: The Network. 2006.

6. Maruschak LM, Beavers R. HIV in Prisons, 2007-08. Bureau of Justice Statistics Bulletin. 2009 Dec:1-12.

7. World Health Organization. People in prisons and other closed settings. 2017. Available from: www.who.int/hiv/topics/prisons/ about/en/.

8. Jürgens R. Effectiveness of interventions to address HIV in prisons. 2007. Available from: www.who.int/hiv/idu/OMS E4Acomprehensive_WEB.pdf.

9. Ehrmann T. Community-based organizations and HIV prevention for incarcerated populations: three HIV prevention program models. AIDS Educ Prev 2002;14(5 Supplement):75-84.

10. Dolan KA, Bijl M, White B. HIV education in a Siberian prison colony for drug dependent males. Int J Equity Health 2004;3(1):7.

11. Odujinrin O, Adebajo S. Social characteristics, HIV/AIDS knowledge, preventive practices and risk factors elicitation among prisoners in Lagos, Nigeria. West Afr J Med 2001;20(3):191-8. 
12. Alves Peres C, Alves Peres R, da Silveira F, Paiva V, Sid Hudes E, Hearst N. Developing an AIDS prevention intervention for incarcerated male adolescents in Brazil. AIDS Educ Prev 2002;14(5 Supplement):36-44.

13. Petrova D, Garcia-Retamero R. Effective evidence-based programs for preventing sexually-transmitted infections: a metaanalysis. Curr HIV Res 2015;13(5):432-8.

14. Fogel CI, Crandell JL, Neevel A, Parker SD, Carry M, White BL, et al. Efficacy of an adapted HIV and sexually transmitted infection prevention intervention for incarcerated women: a randomized controlled trial. Am J Public Health 2015;105:802-9.

15. Fasula AM, Fogel CI, Gelaude D, Carry M, Gaiter J, Parker S. Project power: adapting an evidence-based HIV/STI prevention intervention for incarcerated women. AIDS Educ Prev 2013;25(3):203-15.

16. Fogel CI, Gelaude DJ, Carry M, Herbst JH, Parker S, Scheyette A, et al. Context of risk for HIV and sexually transmitted infections among incarcerated women in the south: individual, interpersonal, and societal factors. Women Health 2014;54(8):694-711.

17. Bauserman RL, Richardson D, Ward M, Shea M, Bowlin C, Tomoyasu N, et al. HIV prevention with jail and prison inmates: Maryland's prevention case management program. AIDS Educ Prev 2003;15(5):465-80.

18. Arp III W. Race, incarceration and HIV/AIDS in Louisiana: risky sexual behavior demands mandatory testing. Race Gender Class 2009;16(1-2):228-37.

19. Ko N-Y, Hsu S-T, Chen C-H, Tsai C-Y, Chu P-J, Huang C-J, et al. A pilot study of HIV education on readiness to change on substance use, AIDS knowledge, self-efficacy for risk reduction among male drug-dependent inmates. Subst Use Misuse 2009;44(3):322-31.

20. Hurd NM, Valerio MA, Garcia NM, Scott AA. Adapting an HIV prevention intervention for high-risk, incarcerated adolescents. Health Educ Behav 2010;37(1):37-50.

21. Velikoshi TINO. Factors influencing the uptake of HIV counselling and testing (HCT) service: the case of the employees of the Namibian Correctional Service at Elizabeth Nepemba Correctional Facility. Stellenbosch: Stellenbosch University; 2013.

22. Motshabi LC, Pengpid S, Peltzer K. HIV counselling and testing utilisation and attitudes of male inmates in a South African prison. SAHARA J 2011;8(3):107-14.

23. Roshanfekr P, Farnia M, Dejman M. The effectiveness of harm reduction programs in seven prisons of Iran. Iran J Public Health 2013;42(12):1430-7.
24. MacDonald M. A study of the health care provision, existing drug services and strategies operating in prisons in ten countries from central and eastern Europe. Helsinki: European Institute for Crime Prevention and Control, affiliated with the United Nations; 2005.

25. Yap L, Butler T, Richters J, Kirkwood K, Grant L, Saxby M, et al. Do condoms cause rape and mayhem? The long-term effects of condoms in New South Wales' prisons. Sex Transm Infect 2007;83(3)219-22.

26. Jürgens R. Interventions to address HIV in prisons: prevention of sexual transmission. Geneva: World Health Organization; 2007.

27. Dolan K, Lowe D, Shearer J. Evaluation of the condom distribution program in New South Wales prisons, Australia. J Law Med Ethics 2004;32(1):124-8.

28. May JP, Williams Jr EL. Acceptability of condom availability in a US jail. AIDS Educ Prev 2002;14(5 Supplement):85-91.

29. Leibowitz AA, Harawa N, Sylla M, Hallstrom CC, Kerndt PR. Condom distribution in jail to prevent HIV infection. AIDS Behav 2013;17(8):2695-702.

30. Harawa NT, Sweat J, George S, Sylla M. Sex and condom use in a large jail unit for men who have sex with men (MSM) and male-to-female transgenders. J Health Care Poor Underserved 2010;21(3):1071-81.

31. Narenjiha H, Rafiey H, Ahmadi K, Assari S, Tavakoli M, Jafari F, et al. Inconsistent condom use among Iranian male drug injectors. Front Psychiatry 2014;4:1-6.

32. Valera P, Chang Y, Lian Z. HIV risk inside US prisons: a systematic review of risk reduction interventions conducted in US prisons. AIDS Care 2017;29(8):943-52.

33. Ammar D, Cordova A. HIV/AIDS in Lebanese prisons: challenges and proposed actions. Int J Prison Health 2014;10(3): 147-54.

34. Wodak A, Cooney A. Effectiveness of sterile needle and syringe programmes. Int J Drug Policy 2005;16:31-44.

35. MacArthur GJ, van Velzen E, Palmateer N, Kimber J, Pharris A, Hope V, et al. Interventions to prevent HIV and hepatitis C in people who inject drugs: a review of reviews to assess evidence of effectiveness. Int J Drug Policy 2014;25(1):34-52.

36. Jürgens R, Ball A, Verster A. Interventions to reduce HIV transmission related to injecting drug use in prison. Lancet Infect Dis 2009;9(1):57-66.

37. Mogg D, Levy M. Moving beyond non-engagement on regulated needle-syringe exchange programs in Australian prisons. Harm Reduct J 2009;6(1):7. 
38. Sawangjit R, Khan TM, Chaiyakunapruk N. Effectiveness of pharmacy-based needle/syringe exchange programme for people who inject drugs: a systematic review and meta-analysis. Addiction 2017;112(2):236-47.

39. Rafiey H, Narenjiha H, Shirinbayan P, Noori R, Javadipour M, Roshanpajouh $\mathrm{M}$, et al. Needle and syringe sharing among Iranian drug injectors. Harm Reduct J 2009;6(1):21.

40. Hellard ME, Aitken C, Hocking J. Tattooing in prisons - not such a pretty picture. Am J Infect Control 2007;35(7):477-80.

41. Dias G, Betteridge G. Hard time: HIV and hepatitis C prevention programming for prisoners in Canada. Toronto: Canadian HIV/ AIDS Legal Network, Prisoners' HIV/AIDS Support Action Network; 2007.

42. Bonnycastle $\mathrm{KD}$. The social organisation of penal tattooing in two Canadian federal male prisons: locating sites of risk for empirically-based health care interventions. Howard J Crim Justice 2011;50(1):17-33.

43. Wickersham JA, Marcus R, Kamarulzaman A, Zahari MM, Altice FL. Implementing methadone maintenance treatment in prisons in Malaysia. Bull World Health Organ 2013;91(2):124-9.
44. Torrens M, Fonseca F, Castillo C, Domingo-Salvany A. Methadone maintenance treatment in Spain: the success of a harm reduction approach. Bull World Health Organ 2013;91(2):136-41.

45. Rich JD, McKenzie M, Larney S, Wong JB, Tran L, Clarke J, et al. Methadone continuation versus forced withdrawal on incarceration in a combined US prison and jail: a randomised, openlabel trial. Lancet 2015;386(9991):350-9.

46. Farnia M, Ebrahimi B, Shams A, Zamani S. Scaling up methadone maintenance treatment for opioid-dependent prisoners in Iran. Int J Drug Policy 2010;21(5):422-4.

47. Larney S, Toson B, Burns L, Dolan K. Effect of prison-based opioid substitution treatment and post-release retention in treatment on risk of re-incarceration. Addiction 2012;107(2): 372-80.

48. Moradi G, Farnia M, Shokoohi M, Shahbazi M, Moazen B, Rahmani K. Methadone maintenance treatment program in prisons from the perspective of medical and non-medical prison staff: a qualitative study in Iran. Int J Health Policy Manage 2015;4(9):583. 